\title{
개발협력 분야 지식공유의 흐름과 국제사회 개발협력 기관들의 동향1)
}

\author{
서 봉 균 (KOICA ODA연구실 상임연구원)
}

\section{목 차}

1. 서론

2. 개발협력 분야 지식공유의 역사적 맥락

3. 지식공유의 개념과 분류

4. 국제사회 개발협력 기관들의 지식공유 활동 및 동향

5. 결론

\section{1. 서 론}

20 세기의 마지막 10 년 동안 국제사회는 지난 50 년간의 개발원조 역사를 반성하면서, 개발도 상국의 효과적인 개발을 위해서는 무엇이 실질적으로 필요한 것인지에 대하여 많은 고민들을 하게 되었다. 그리고 이러한 고민들에 대한 해결책 중의 하나로 제시되고 있는 것이 바로 효과 적인 개발을 위해서는 자본과 노동 등 물질적인 자원의 투입뿐만 아니라, 비물질적인 지식 (Knowledge)2)을 활용하고 이를 선진국과 개발도상국 혹은 개발도상국들 상호간에 공유 (Knowledge Sharing, $\mathrm{KS}$ )하는 것이 필요하다는 시각이다.

1) 본 논문은 KOICA에서 2012년에 발간한 '지식공유를 통한 개발협력 방안: KOICA의 내부적 지식공유 활성화를 중심으로(서봉균)' 연구보고서를 요약 보완한 것이다.

2) 지식(Knowledge)과 경험(Experience)은 서로 간에 의미상의 차이가 있을 수는 있으나 본 보고서에는 이를 구분 하지 않고 혼용하여 쓸 예정이다. 경험을 과거에 일어난 일을 통하여 배우게 된 교훈(Lessons learned)의 의미 로 생각한다면 이를 지식의 범주에 넣어도 무방할 것으로 판단된다. 
유용한 지식을 활용하고 이를 상호 공유하는 것은 개발을 효과적으로 수행하고 그 목표를 달 성하기 위해 매우 필수적인 요소라고 할 수 있다. 새천년개발목표(MDGs)3)를 비롯하여 국제사 회의 다양한 개발주체들이 추구하는 개발도상국의 경제성장, 빈곤퇴치, 환경보전 등의 목표들 은 기존처럼 단순히 물질적인 원조만을 통해서는 충분히 달성될 수 없으며, 개발을 촉진할 수 있는 지식을 활용하고 수원국과 이러한 지식을 상호 공유하는 것이 개발도상국의 발전에 더욱 중요한 요소라는 인식이 국제사회의 개발협력 분야에서 공감대를 형성해 가고 있다. ${ }^{4)}$

특히 2010년 서울에서 열린 G20 정상회의에서 채택된 ‘동반성장을 위한 서울개발의제’ 는 개 발협력 분야에서 지식공유를 개발도상국의 발전에 필수적인 9 대 분야(9 Pillars)의 하나로서 명 시적으로 상정하고 있다. 이에 본 연구에서는 국제사회의 지식공유 흐름의 역사적 맥락과 개념, 그리고 이를 바탕으로 대표적인 개발협력 기관들의 지식공유와 관련된 활동과 동향을 살펴보고 자 한다.

\section{2. 개발협력 분야 지식공유의 역사적 맥락}

서론에서도 잠시 설명했다시피 개발도상국의 발전에 있어 지식의 중요성에 대한 강조가 21세 기의 최근 10 년 동안에 나타난 새로운 흐름이기는 하지만, 이러한 흐름의 근원을 추적해 보면 일반적인 상식이나 혹은 개발원조의 역사적인 측면에서 볼 때 지식은 언제나 성공적인 개발을 위한 가장 중요한 수단 중의 하나로 여겨져 온 것이 사실이다. 이는 많은 학자들 사이에서 개발 원조의 시발점으로 평가받고 있는 제 33대 미국 대통령 헨리 투르만의 1949년 연설에서도 찾아 볼 수 있다.

이제 우리 모두는 우리가 이룩한 과학과 산업의 발전이 세계의 저개발 국가들에게 도움이 될 수 있도록, 새롭고도 대담한 프로그램들을 시작해야만 한다. 현재 전 세계 인구의 절반 이상은 매우 비참한 환경 속에서 살아가고 있다. 역사상 처음으로 인류는 고통 받고 있는 사람들을 구

3) 새천년개발목표(MDGs)는 다음의 8가지로 구성되어 있다. (1) 절대빈곤 및 기아퇴치 (2) 보편적 초등교육 달성 (3) 남녀평등 및 여성권익 향상 (4) 아동 사망률 감소 (5) 모성 보건 향상 (6) HIV/AIDS, 말라리아 등 질병 퇴치 (7) 지 속가능한 환경 보전 (8) 개발을 위한 범지구적 파트너십 구축

4) 물론 개발도상국의 발전을 위하여 지식의 활용을 더욱 중요시하는 접근법이 국제사회에서 완전한 합의점에 도달 한 상태는 아니다. 뒤에서 살펴보겠지만 이는 개발협력의 여러 분야 중에서 지식관리(KM)내지는 지식공유(KS)와 관련된 분야라고 할 수 있는데, 이것은 아직 실험적인 소개의 단계라고 할 수 있다. 
할 수 있는 지식과 기술을 보유하게 되었다. 이러한 사람들을 돕기 위하여 필요한 물질적인 자 원은 한정되어 있지만, 지식과 기술이라고 하는 무형의 자원은 계속 증가하고 있으며 결코 고갈 되지 않을 것이다. (Truman, 1949)

개발원조의 역사에서 초기부터 언급되었던 지식과 기술의 중요성에 대한 강조에도 불구하고, 적어도 20세기 후반까지는 지식이 개발에 필요한 실질적이고 중요한 요소로 인식되어져 오지는 않았다. 이는 경제성장과 개발을 자본과 노동이라는 물질적인 생산요소의 투입에 따른 결과로 생각하는 전통적인 경제이론에 기반을 둔 개발경제학의 시각이 오랫동안 영향을 미쳐온 때문이 라고 할 수 있을 것이다. ${ }^{5)}$

그러나 20세기 후반부터 정보통신기술(Information \& Communication Technology)의 혁명을 중심으로 하는 지식과 관련된 새로운 현상들이 나타나기 시작하였으며, 이는 개발협력 의 분야에도 지대한 영향을 미치게 되었다. 이러한 현상의 대표적인 것들로는 우선 세계화 (Globalisation), 정보통신기술(ICT)의 급속한 발전, 지식 자체를 새로운 생산요소로 상정하는 - 오히려 기존의 자본과 노동보다 더 중요한 생산요소로 여기는 - 새로운 지식경제학의 대두, 지식을 이익창출을 위한 기업경영의 핵심 요소로 간주하여 이를 축적하고 내부적으로 공유하는 것에 초점을 맞추는 지식관리(Knowledge Management) 경영기법 등을 들 수 있다.

한편 위에서 언급한 새로운 현상들은, 개발협력 분야에서 효과적인 개발원조를 위하여 수원국 중심의 개발을 강조하는 협력의식(Partnership), 주인의식(Ownership) 및 역량개발 (Capacity Development) 등을 강조하는 흐름과 맞물리면서, 국제사회의 개발주체들이 지식 기반 원조(Knowledge based aid)라는 것에 관심을 가지게 하는 계기가 되었다.

그리고 현대사회의 지식 자체를 강조하는 흐름들을 바탕으로 개발협력 분야에 있어서도 이를 적극적으로 도입하고자 하는 움직임들이 나타나게 되었다. 이러한 움직임을 단적으로 보여주는 사건으로는 1996년 당시 세계은행의 총재였던 울펜손(James Wolfensohn)의 연설을 들 수 있 다. 1996년 세계은행과 국제통화기금(International Monetary Fund)의 연차총회에서 올펜 손 총재는 개발을 위한 지식의 중요성을 강조하는 기념비적인 연설을 하게 되었고, 이 연설에서

5) 개발은 필연적으로 지식의 활용과 학습의 과정이라는 인식이 경제학자들 사이에 서서히 스며들어 가고 있다. 그러 나 여전히 이들은 지식과 학습이 개발에 있어 실질적인 열쇠가 된다는 연구를 무시하는... 기술적인 모델 (mechanical model)에 사로잡혀 있다는 것 또한 사실이다.(Boulding, 1966) 
세계은행은 앞으로 지식은행(Knowledge Bank)으로써의 역할을 수행할 것임을 천명하였다.

우리는 오랫동안 개발을 위한 교훈들을 연구하고 이를 전파하기 위하여 노력해 왔다. 그리고 정보의 혁명은 그 결과들을 더욱 많은 사람들에게 확산시킴으로써, 이러한 노력의 가치를 높이 고 있다. 이제 우리는 개발과 관련된 정보와 경험을 모으고 이를 공유하기 위하여 필요한 시스 템들을 갖추어 나갈 필요가 있다. 그리고 세계은행은 이를 위하여 지식은행(Knowledge Bank) 의 역할을 할 것이다. Wolfensohn, 1996)

사실 울펜손 총재의 연설은 그 당시 개발원조의 낭비와 비효율성으로 인하여 세계은행이 직면 하고 있던 개혁의 요구에 대한 화답의 성격을 가진 것이기도 하였다. 그러나 결과적으로 이 연 설은 세계은행을 비롯한 국제사회의 여러 개발협력 기관들이 내외부적인 개발협력 사업의 수행 과정에 있어서, 개발 지식을 활용한 효과적인 개발이라고 하는 새로운 접근을 시도하게 하는 계 기가 되었다.

이와 관련하여 개발협력 분야에서 개발과 지식 간의 관계에 대한 인식의 전환을 촉발한 이정 표로써 평가받고 있는 세계은행(World Bank)의 보고서 '개발을 위한 지식(Knowledge for Development) ${ }^{6}$ )은 아래와 같은 선언적인 문장을 통하여 지식이 개발에 미치는 영향력을 강조 하고 있다.

지식은 빛과 같은 것이다. 아무런 무게도 없고 잡을 수도 없지만 손쉽게 전 세계로 퍼져나가 인류의 삶을 밝혀줄 수 있다. 그러나 수십억명의 사람들은 여전히 빈곤이라는 어둠속에 갇혀 지 내고 있다.(World Bank, 1999)

이후 개발의 과정에서 지식의 중요성을 강조하고 이의 활용과 상호 공유를 더욱 촉진해 나가 야 한다는 요구와 관심은 계속 증가하고 있으며, 다양한 국제회의와 선언들에서 이를 재차 강조 하고 있는데 이 중 주목할 만한 몇 가지를 살펴보면 다음과 같다.

6) 세계은행은 국제개발 분야의 주요 이슈를 선정하여 매 2년마다 세계개발보고서(World Development Report)라 는 보고서를 발간하고 있는데 '개발을 위한 지식(Knowledge for Development)' 은 1998/99에 해당하는 보고서 이다.

7) 일반적으로 알려진 새천년개발목표(Millenium development goals)는 'UN 새천년선언의 이행을 위한 행동계획' 의 부록(Annex)으로 첨부된 문서이다. 
여기에는 2000년 UN 새천년선언에 따른 '새천년선언의 이행을 위한 행동계획(Road map towards the implementation of the United Nations Millenium declaration)' 7), 2010 년 남남협력과 역량개발을 위한 보고타 고위급 회의의 '보고타 선언(Bogota Statement Towards Effective and Inclusive Development Partnerships)', 2010년 G20 서울 정상 회의의 '서울개발의제(Seoul Development Consensus for Shared Growth)', 부산 세계개 발원조총회(HLF-4)의 '부산 파트너십 선언(Busan Partnership for Effective Cooperation)' 등이 있으며, 이의 자세한 내용은 다음의 [표 1]에서 확인할 수 있다.

\section{〈표 1〉 개발을 위한 지식과 경험의 활용 및 공유와 관련된 주요 국제선언}

\begin{tabular}{|c|c|c|}
\hline 연도 & 선언문 & 내용 \\
\hline 2000 & $\begin{array}{l}\text { UN 새천년선언의 이 } \\
\text { 행을 위한 행동계획 }\end{array}$ & $\begin{array}{l}\text { 정보통신기술은 동반성장과 지속가능한 개발을 촉진하고 빈 } \\
\text { 곤감소를 위한 강력한 도구가 될 수 있다. }\end{array}$ \\
\hline 2010 & $\begin{array}{l}\text { 효과적이고 포용적인 } \\
\text { 개발 파트너십을 향 } \\
\text { 한 보고타 선언 }\end{array}$ & $\begin{array}{l}\text { 개발의 모든 단계에 걸쳐 남남 간의 상호학습은 지식과 경험 } \\
\text { 의 공유 그리고 기술의 전파를 통한 개발도상국 역량개발의 } \\
\text { 핵심적인 요소이다. }\end{array}$ \\
\hline 2010 & $\begin{array}{l}\text { 동반성장을 위한 } \\
\text { 서울개발의제 }\end{array}$ & $\begin{array}{l}\text { 남북협력, 남남협력 그리고 삼각협력을 통한 개발경험의 공 } \\
\text { 유는 개발의 과정에서 직면하는 문제들에 대한 가장 적절하 } \\
\text { 고 효과적인 해결책 제시에 기여한다. }\end{array}$ \\
\hline 2011 & $\begin{array}{c}\text { 효과적인 개발협력을 } \\
\text { 위한 부산 } \\
\text { 파트너십 선언 }\end{array}$ & $\begin{array}{l}\text { 기존의 재정적인 지원을 넘어서 모든 개발주체들의 지식과 } \\
\text { 개발경험은 지속가능한 개발의 원천이다. }\end{array}$ \\
\hline
\end{tabular}

\section{3. 지식공유의 개념과 분류}

개발협력 분야에서 초기에 강조되었던 지식관리 혹은 지식공유라는 것은 처음 일반 기업의 경 영기법에서 나온 개념이라 할 수 있다. 1970년대 이후 새로운 정보통신기술의 발전과 급격한 구조조정의 과정 속에서 기업들은 수익개선을 위하여 인력감축을 단행하였고, 이는 기존에 사 내에 축적되어있던 기업경영에 필수적인 지식들을 사장시키는 부작용을 낳게 하였다.

이에 따라 기업들은 지식이 기업의 경쟁력에 필수적인 요소임을 자각하고, 이를 두 가지 방향 으로 기업경영에 접목하고자 하였다. 첫 번째는 기술적인 방식 위주의 지식관리(KM)이다. 이는 
사내에 이미 존재하는 지식들이 무엇인지를 파악하고 문서화하며, 정보통신기술을 이용하여 이 를 데이터베이스에 축적하는 것이다.

두 번째는 사회적인 방식 위주의 지식관리이다. 실제로 중요한 지식은 명시적이고 문서화되어 있는 것보다는 직원들의 경험과 같이 문서화될 수 없고 개인들의 머릿속에서만 존재하는 암묵 적인 지식이라는 것이다. 따라서 이러한 지식들을 활용하기 위해서는 조직원 및 팀 간에 지식과 경험을 공유하고 기업 내의 조직적인 학습(Organizational Learning)을 통하여 이를 습득하 는 것을 지원하는 것이 중요하다.

기업경영의 하나로 지식관리기법이 성숙되어지면서 '지식관리(KM)'는 차츰 '지식공유(KS)' 라는 용어로 대체되기 시작하였다. 이는 지식관리의 기술적인 접근 방식보다 사회적인 접근 방 식이 더욱 강조되는 추세를 반영한 결과라고 할 수 있다.

\section{〈표 2〉지식관리와 지식공유의 개념}

\begin{tabular}{|c|c|}
\hline 구분 & 설명 \\
\hline $\begin{array}{c}\text { 지식 관리 } \\
\text { (Knowledge } \\
\text { Management, KM) }\end{array}$ & $\begin{array}{l}\text { 데이터베이스의 확충, 인트라넷의 설치 등 기반시설 강화, 정책의 } \\
\text { 수립, 운영 프로세스의 확립 등 지식을 축적하고 공유하기 위하여 } \\
\text { 기술적인 접근을 조직의 운영에 적용하는 것 }\end{array}$ \\
\hline $\begin{array}{l}\text { 지식 공유 } \\
\text { (Knowledge } \\
\text { Sharing, KS) }\end{array}$ & $\begin{array}{l}\text { 기술적인 접근보다는 사회적이고 인간중심적인 관점에서 조직의 내 } \\
\text { 외적으로 지식을 창조하고, 공유하기 위한 네트워크를 구축하고, } \\
\text { 문화를 조성하는 것 }\end{array}$ \\
\hline
\end{tabular}

한편 1990년대 이후 개발협력 분야에서는 기관들의 운영방식을 개선하고, 수원국의 주인의식 (Ownership), 협력의식(Partnership), 참여(Participation), 역량개발(Capacity Development)을 강화하여 개발협력 사업의 효과성을 높여야 한다는 인식이 확산되고 있었다. 이러한 조류와 기업경영의 지식공유 그리고 정보통신의 발전이 결합되면서 개발협력 분야에서 도 효과적인 개발을 위한 수단의 하나로써 지식공유라는 개념이 도입되게 되었다.

현재 지식공유를 강조하고 있는 개발협력 분야의 분위기 속에서 다양한 기관과 선언들이 지식 공유의 개념을 정의하고 있다. 이 중 주목할 만한 몇 가지를 살펴보면 [표 3]과 같다. 


\section{〈표 3〉 개발을 위한 지식공유의 개념}

\begin{tabular}{|c|c|}
\hline 기관 & 개념 \\
\hline 세계은행 & $\begin{array}{l}\text { - 연구와 경험을 통한 지식의 체계적 습득 } \\
\text { - 조직화와 축적을 통한 지식과 정보에의 원활한 접근 } \\
\text { - 상호교환을 통한 지식의 전수와 전파 }\end{array}$ \\
\hline UNDP & $\begin{array}{l}\text { 특정한 상황 속에서 문제를 해결하고, 문제해결을 위한 능력을 발휘 } \\
\text { 할 수 있도록 정보가 해석되고 사용될 때 이를 지식이라고 한다면, } \\
\text { 지식의 공유는 문제해결을 위하여 정보를 사용(적용)할 수 있는 능력 } \\
\text { 을 공유하는 것을 의미 }\end{array}$ \\
\hline $\begin{array}{c}\text { G20 개발그룹 } \\
\text { (Working Group) }\end{array}$ & $\begin{array}{l}\text { - 다양한 국가에서 적용되고 증명된 개발모델과 해결책들의 공유 } \\
\text { - 개발 전문성 및 증거기반 공공정책과 관련된 가치있고 문서화되기 } \\
\text { 어려운 정보에 대한 직접적인 접근 } \\
\text { - 개인, 조직, 사회가 전체적으로 자신들의 역량을 강화하기 위하여 } \\
\text { 다른 사람들의 지식을 적용하는 과정 }\end{array}$ \\
\hline
\end{tabular}

지식 자체가 효과적인 개발을 위한 핵심적인 요소라는 인식이 확산되면서 국제사회의 개발협 력 기관들은 개발에 유용한 지식을 공유하기 위한 다양한 방법들을 모색해 오고 있다. 지식의 공유는 초기에 개발협력 기관들이 조직의 내부역량을 강화하기 위한 목적으로 시작하였으나, 차츰 개발지식을 외부의 다른 기관 및 수원국들과 공유하여 외부의 개발역량을 강화하기위한 목적으로 옮겨가게 되었다. 이것은 다시 말해 지식공유가 크게 내부적 지식공유(Internal Knowledge Sharing)와 외부적 지식공유(External Knowledge Sharing)로 분류될 수 있음 을 의미하는 것이다.

우선 내부적 지식공유란 기관이 개발사업과 운영을 효과적으로 하기위하여 조직 내의 지식공 유를 활성화하는 다양한 활동들을 의미한다. 개발협력 기관들은, 일반적인 기업들이 효과적인 조직 운영을 위하여 기업경영에 지식관리 $(\mathrm{KM})$ 기법을 적용하는 것과 유사하게, 데이터베이스 (DB)의 확충, 학습을 통한 직원 역량강화, 그리고 인트라넷(intranet) 및 화상회의를 활용한 조 직 내 직원 및 부서들 간의 지식 공유 등의 방식으로 자신들의 내부적인 조직 운영 자체를 효과 적으로 수행하고자 하였다.

다음으로 외부적 지식공유는 내부적 지식공유를 넘어서 개발협력 기관들의 주된 관심사가 되 고 있다. 외부적 지식공유란 조직 외부의 파트너 및 주체들과 개발지식을 상호공유하기 위한 남 북협력(South-North Cooperation), 남남협력(South-South Cooperation), 삼각협력 (Triangular Cooperation) 등의 다양한 활동들을 의미한다. 이는 개발협력 기관들이 효과적인 
조직 운영이라는 틀을 넘어서 효과적인 개발이라는 자신들의 본래 목적을 달성하기 위하여, 외 부적으로 개발주체들 간에 필요한 지식의 상호 공유를 시도하는 것이다.

이는 공여국의 원조가 효과를 거두기 위해서는 수원국들이 스스로 개발의 주체가 될 수 있도 록 자체적인 개발역량을 강화하는 것이 중요하며, 이러한 역량의 개발(Capacity Development)을 위해서는 수원국들이 자신들의 여건에 맞는 지식을 축적하고 적용하는 것이 필요하기 때문이다.

그러나 개발협력 기관들이 내부적 지식공유를 활성화하여 조직의 운영과 원조사업을 효과적 으로 수행하려는 목적은, 궁극적으로 외부적 지식공유라는 개발협력 사업을 통해 수원국의 역 량개발과 효과적인 개발협력의 결과를 낳기 위한 노력과 연결된다는 점에서 둘 사이는 서로 긴 밀하게 연결되어있는 것이다.

\section{〈표 4〉지식공유의 분류}

\begin{tabular}{c|c}
\hline 분류 & 설명 \\
\hline 내부적 지식공유 & $\begin{array}{l}\text { 기관이 개발사업과 운영을 효과적으로 하기위하여 조직 내의 지식 } \\
\text { 규를 활성화하는 다양한 활동들을 의미 }\end{array}$ \\
\hline 외부적 지식공유 & $\begin{array}{l}\text { 조직 외부의 파트너 및 주체들과 개발지식을 상호공유하격, 위함남녑력, 삼각협력 등의 다양한 활동들을 의미 } \\
\text { 박 }\end{array}$ \\
\hline
\end{tabular}

\section{4. 국제사회 개발협력 기관들의 지식공유 활동 및 동향}

여기서는 문헌들을 통해 타 기관들에 비하여 상대적으로 활발한 지식공유 활동을 하고 있는 것으로 판단되는 개발협력 기관들을 기관의 형태(다자기구, 양자기구, 비정부기구)와 지역적인 안배(유럽 지역, 북미 지역, 아시아 지역 등)를 고려하여 6 개 기관을 선택하고 이들의 활동과 동 향을 살펴보고자 한다.

\section{1) 세계은행(World Bank)}

세계은행의 지식공유는 관련되어 있기는 하지만 서로 간에 상이한 두 가지 측면에서 다루어져 
왔다. 하나는 정보통신 기술을 활용하여 지식공유를 위한 조직의 변화를 추구하는 측면이며, 다 른 하나는 축적된 지식들을 활용하여 개발도상국의 경제성장을 촉진하는 것이다. 그리고 세계 은행 연구소(WBI)와 각 지역 별 지식공유 전문가들(knowledge and learning specialists)이 지식공유를 위한 전략을 담당하고 있다.

세계은행은 문서 등으로 직원들에게 지식공유의 중요성을 설명하기 보다는 상호교류 및 지식 공유에 유용한 도구와 기술의 활용 등을 통하여 은행이 축적해 온 지식들을 적재적소에 제공하 는 것을 중요시 여기고 있다. 또한 외부의 개발파트너들과의 대화 및 지식공유를 위한 컨퍼런스 나 세미나 등의 장을 마련하는 것에도 주안점을 두고 있다.

세계은행의 지식공유 전략은 조직의 내외부에 걸쳐 매우 다양한 방식으로 다루어지고 있다. 여기에는 사장되고 있는 지식의 복원, 반복되는 업무의 감소, 세계은행이 가지고 있는 지식에 대한 접근성 강화를 통하여 외부의 개발파트너들에게 지원되는 서비스의 질적 향상, 국제적인 성공사례를 공유할 수 있는 세계은행의 비교우위 강화, 역량개발, 조직의 분권화와 지식공유 업 무에 대한 인센티브 제공 등이 포함된다.

여기서 핵심적인 것은 외부의 개발파트너들로부터 배우며, 더 좋은 결과를 얻기 위하여 이들 의 요구를 세계은행이 수행하고 있는 여러 프로그램들에 적용하는 것이다. 이러한 활동들은 지 식은행(Knowledge Bank)을 지향하기 위한 다음의 3 가지 전략적인 주제(three strategic pillars)에 맞추어 분류될 수 있다.

- 조직운영을 지원하기 위한 지식: Thematic group, Advisory services

- 외부 개발파트너와의 지식공유: GDLN(Global Development Learning Network)

- 수원국의 역량개발: 세계은행 연구소(World Bank Institute), The Development Gateway, GDN(Global Development Network),

지식은행(Knowledge Bank)으로의 전환이라는 비전을 달성하기 위하여 세계은행이 역점을 두고 있는 것으로는 다양한 개발지식 및 성공/실패 사례들을 공유하기 위한 지식공유 네트워크 를 구축하는 것이다. 예를 들어 세계은행은 핵심주제들에 대한 지식공유를 지원하기 위하여, 기 존에 이미 비공식적으로 지식공유를 위하여 존재하던 네트워크를 공식화한, 약 80여개의 주제 그룹(Thematic group)을 운영하고 있다. 
이러한 주제 그룹의 대표적인 케이스로는 'Education Knowledge Management System(EKMS)'를 들 수 있는데, EKMS에서는 전 세계 약 300여명의 교육 분야의 직원 및 관련자들이 모여 성공사례 수집, 훈련과정과 Advisory service 제공, 관련 지식의 통합, 토론 의 활성화, 인트라넷을 통한 정보의 공유 그리고 사전에 문제 인식을 하는 네트워크이다.

'Advisory service(help desk)' 는 관련자들이 은행의 전문지식에 쉽게 접근할 수 있도록 원 스톱 서비스(one-stop service)를 제공하는 것이다. 이것의 주된 목적은 전문지식에 대한 질문 에 즉각적으로 응답하는 서비스를 제공하는 것이지만, 이외에도 자주 요청되는 정보들에 대한 데이터베이스를 만들고, 이메일을 활용하여 관련 정보들을 사전에 제공하는 기능도 수행하고 있다.

다음으로 축적된 지식을 외부의 개발파트너 및 이해관계자들과 공유하기 위한 세계은행의 노 력은 'Development Gateway', 'Global Development Network(GDN)' 그리고 'Global Development Learning Network(GDLN)' 이라는 세 가지 프로젝트로 나타나고 있다. 'Development Gateway' 는 사용자들이 개발과 관련된 다양한 이슈들에 접근할 수 있게 하 며, 의견교환의 장을 마련해 주는 것을 목적으로 하는 인터넷 포털 사이트(portal site)이다.

$\mathrm{GDN}$ 은 개발과 관련된 연구를 지원하고 그 결과물들을 공유하며, 개발도상국의 연구능력을 향상시키고 지원하기 위한 목적의 네트워크이다. 또한 아이디어 단계의 다양한 개발관련 연구 들이 실질적으로 실행가능한 단계로까지 발전하는 것을 지원하는 기능도 수행하고 있다. GDLN은 원거리 학습(distance learning), 세미나 그리고 국가 간 의사결정자 사이의 대화 등 의 방식으로 지식공유와 학습을 지원하는 네트워크이다. GDLN의 핵심은 개발도상국의 언어와 현지사정에 적합한 내용들을 다루는 학습 프로그램들을 제공하여, 세계은행을 비롯한 어느 특 정한 기관에 소속된 것이 아니라 독립적으로 운영된다는 점이다.

\section{2) 아시아 개발은행(ADB)}

아시아 개발은행은 지역의 빈곤퇴치와 개발을 촉진하기 위해서는 개발관련 지식의 축적과 공 유가 필수적임을 인식하고, 이를 위하여 개발지식의 상호학습과 주요 제공자가 되기 위한 노력 을 기울이고 있다. 이와 관련하여 아시아 개발은행의 장기 전략보고서(Long-Term Strategic Framework for 2001-2015)에서는 지식의 생산과 공유가 빈곤퇴치의 전제조건임을 확인하면 서 아래와 같이 명시하고 있다. 
아시아 개발은행은 조직의 내외부에 있는 다양한 자원, 기술 그리고 지식을 활용하여 지식에 기반을 한 학습조직으로 변화해야 한다. 또한 우리 자신과 외부 파트너의 경험으로부터 배우고, 회원국, 조직 내 직원 그리고 외부의 개발파트너들 사이에 이러한 경험들을 확산시키기 위한 역 량을 개발해야 한다.

이에 따라 내외부적인 지식관리와 공유를 전담하는 부서인 'Regional and Sustainable Development Department(RSDD)' 가 만들어 졌으며, 이 후에 지식공유 활동을 감독하고 가 이드라인을 제공하기위한 'Knowledge Management Committee' 와 이를 관장하기 위한 부 총재직(Vice-presidency)이 신설되었다.

초기에 지식공유를 아시아 개발은행에 정착시키는 과정에서 여러 운영 및 지원 부서들 (Operational and Supporting departments)에서 선발된 인원들로 실무그룹(Working group)이 구성되었다. 그리고 실무그룹에서는 지식공유의 개념, 향후의 계획과 계획을 위해 필 요한 요소 등이 논의되었으며, 이의 결과물로 제시된 것이 아시아 개발은행의 지식관리 전략보 고서(KM Framework)이다.

위에서 언급된 지식관리 전략보고서에서는 지식공유를 정착시키기 위하여 필요한 5 가지 실 행계획(Action Plan)을 다음과 같이 제시하고 있다.

- 지식공유를 위한 조직문화 개선

- 개발관련 연구의제 선정 강화

- 지식공유를 위한 업무 프로세스와 정보통신 기반시설 개선

- 개발협력 전문가 커뮤니티 활성화

- 외부의 이해관계자 및 개발 파트너와 지식공유를 확대

위의 5 가지 실행계획을 구체화하기 위한 예를 살펴보면, 우선 조직의 지식공유 문화를 향상 시키기 위해 직원들의 지식공유 활동에 대한 인센티브 체계를 확립하였으며, 분야별, 주제별 지 식공유를 촉진하기 위하여 10개의 공식적인 '개발협력 전문가 커뮤니티(Community of Practice)' 와 23개의 비공식적인 개발협력 전문가 커뮤니티를 설치하고, 이 개발협력 전문가 커뮤니티들에게는 개발파트너 및 관련 회원국들과 내외부적인 지식공유를 위한 지원을 하고 있 다.

아시아 개발은행은 축적된 지식에 대한 접근성을 강화하기위한 다양한 프로젝트를 수행하고 
있다. 이러한 프로젝트들로는 웹에 기반을 한 새로운 인트라넷을 개발하여 다양한 데이터베이 스에의 접근을 원활하게 하는 것, 부서별/분야별/주제별 지식을 습득하고, 공유하며, 확산시키 기 위한 지식관리 프로그램(KM applications)을 개발하는 것 그리고 경제/환경/사회와 관련된 지리 정보(Spatial information)의 활용을 위한 지리 데이터베이스(Mapview)를 개발하는 것 등을 들 수 있다.

또한 지식공유를 위한 외부 네트워크를 확대하고 타 기관들과의 파트너십을 강화하기 위하여, 컨퍼런스나 포럼 등을 활용해 다양한 분야의 전문가들과 기관들로 구성된 약 300 여개의 네트워 크에 참여하고 있다. 그리고 'Center for Learning, Information, Communication, and Knowledge(CLICK)'을 설립하여 지역의 회원국 및 외부 개발파트너들의 필요에 부합하는 개 발관련 최신지식들을 공유하고 확산시키기 위한 원거리 학습(Distance learning)을 지원하고 있다.

\section{3) 영국 국제개발청(DFID)}

DFID 지식공유의 비전은 MDGs와 그 밖의 개발목표들을 달성하기 위하여 유용한 지식을 모 으고 이의 할용을 극대화하는 것이다. 이를 달성하기 위한 지식공유 전략에서는 업무의 효과성 과 효율성을 높이기 위한 시도를 하고 있는데, 이에는 새로운 정보통신 기술의 활용을 위한 내 부 역량 강화, 증가하는 지식정보 관련 업무에 대한 대처, 복잡해지는 개발협력 환경에 대응하 기 위한 직원역량 개발 등이 포함된다.

DFID의 지식공유 전략은 명시적 지식과 암묵적 지식 모두에 걸치는 폭넓은 범위를 다루기 위 한 다양한 지식공유 도구들의 사용을 권장하고 있다. 이러한 도구들의 예로는 업무와 관련된 핵 심적인 주제와 과정들에 관한 이해를 높이기 위한 'how to' 노트를 개발하고 활용하는 것, 약 70 여개의 비공식적인’ 개발협력 전문가 커뮤니티(Community of Practice) ‘를 운영하는 것 그리고 다양한 주제들을 아우르는 직원 세미나 등을 들 수 있다. 그리고 이러한 도구들을 활용 하기 위한 직원 교육이 제공된다.

한편 지식공유 역량이 성과관리 시스템의 중요한 부분을 차지하고 있기는 하지만, DFID에서 지식공유는 업무에 체계적으로 적용되기보다는 업무를 위한 다양한 지식들을 자료의 형태로 다 운로드받는 방식으로 활용되고 있다. 이와 관련하여 인트라넷은 DFID의 내부적 지식공유에 있 어서 중요한 역할을 하고 있는데, 임명된 편집직원들은 인트라넷에 올라온 자료들의 기여도를 
모니터링하고 여러 기준들을 정하여 신뢰성을 확보하고 있다. 초기에 자료를 공유하던 역할과 더불어 인트라넷은 점점 더 핵심적인 업무를 지원하고 관리의 효율성을 위한 대화의 장으로써 의 역할을 담당하고 있다.

DFID는 'GDNet', 'SciDev', 'Id21', 'ELDIS' 그리고 'Livelihoods Connect' 와 같은 다 양한 외부적 지식공유 네트워크들을 지원하고 있다. 이 중에서 'Id21'은 이메일을 통한 개발관 련 교류와 연구결과 제공서비스에 강점을 지니고 있으며, 'Livelihoods Connect' 는 지속가능 한 삶의 질 개선과 관련된 지식들을 교류하는 것에 목적을 두고 있는 네트워크라 할 수 있다.

\section{4) 캐나다 국제개발청(CIDA)}

CIDA는 원조효과성 강화라는 기관차원의 목표를 달성하기 위하여 효과적인 지식기반 조직으로 변화하려는 노력을 기울이고 있다. 이와 관련하여 $\mathrm{CIDA}$ 의 전 직원들에게 적용되는 지식공유 전략의 비전은 다음과 같다.

- 학습과 지식 공유의 가치를 높임

- 전문지식에 대한 접근성을 강화할 것

- 지속가능한 개발과 빈곤감소를 위하여 유용한 지식을 보유

- 경험으로부터 지속적으로 배우기

나아가 CIDA는 조직이 가지고 있는 지식을 국내외의 개발파트너 및 수원국들에게 유용한 지 식으로 만들려는 시도를 하고 있다.

CIDA의 지식관련 업무는 지식관리 담당관(KM Secretariat)으로 임명된 직원들에 의하여 수 행되어 왔으며, 관련 업무가 증가함에 따라 담당관은 조직 내의 직원들이 순차적으로 맡아 왔 다. 그리고 조직의 효과성을 높이는데 있어서 지식공유의 중요성이 더욱 강조됨에 따라 최근에 지식관리 담당관은 성과관리부서(Performance Management Division)의 일부분이 되었다.

CIDA의 지식공유 프로그램들은 CIDA가 수행하고 있는 다양한 사업과 정책의 성과를 높이는 것을 목적으로 하고 있으며, 이를 위하여 다음의 3 가지 영역에서 노력을 기울이고 있다.

- 상위관리자 차원에서 지식공유 활동들을 설득하고 촉진하기

- 인사관리 차원에서 지식공유 활동들에 대하여 지원하고 포상하기

- 업무에 지식공유를 적용시킬 수 있는 직원들의 역량을 증진하기 위하여, 업무수행 과정에 다 양한 도구(tool)들을 제공하기 
또한 지식관리 담당관들은 위의 3 가지 영역을 바탕으로 다음과 같은 지식관리 업무를 수행한다.

- $\mathrm{CIDA}$ 의 지식공유 역량을 촉진하고 개발하기

- 지식공유를 위한 프로세스를 활성화하고 지원하기

- 다양한 개발 파트너들과 지식공유 사업을 수행하기

CIDA는 지식공유를 위하여 'AAR(After Action Review)' 나 'Peer Assist' 같은 다양한 도 구들을 활용하고 있으며, 직원들에게 이러한 도구들에 대한 교육을 실시하고 있다. 그리고 발표 회, 포럼, 원탁회의 등의 방법으로 분야별, 주제별 이슈들을 다루는 공식적인 지식공유 네트워 크를 운영하고 있다.

CIDA는 지식공유에 대한 임직원들의 관심을 고취하기 위하여 다양한 활동들을 하고 있는데, 이 중에는 상위직급에 대한 인사관리에 있어 지식공유의 노력을 평가하기도 하고, 직원들의 채 용과정에 있어서도 지식공유 역량이 고려되고 있다. 한편 '워크샵', '세미나', '오전회의 (Coffee Morning)' 등의 다양한 비공식적인 지식공유 활동들을 지원하고 있다.

지식공유를 지원하기 위한 시스템 중의 하나로는 'CIDA 인터넷 사이트' 를 들 수 있는데, 이 것은 최근에 외부의 개발파트너, 현장 전문가, 내부적인 지식공유 네트워크까지를 아우르는 지 식공유를 위한 웹 기반(Web enabled)의 엑스트라넷(Extranet)으로 발전하였다.

또 다른 지원 시스템으로는 평가실(Evaluation Division)에서 운영하는 평가 자료들에 대한 데이터베이스와 지식관리 담당관이 운영하는 업무 데이터베이스가 있으며, 다양한 '개발협력 전문가 커뮤니티(Community of Practice)' 와 실무자들이 자신들의 지식공유 활동을 위하여 이러한 시스템들을 사용하게 하고 있다.

CIDA의 지식공유 활동의 예들로는 다음과 같은 것들이 있다.

- 분야별, 주제별에 따른 공식적인 '지식공유 개발협력 전문가 커뮤니티(Community of Practice)' 운영

• 부서의 당면과제에 대한 외부 전문가와의 모임 및 사업종료 평가

- 지식공유와 학습에 필요한 도구들의 원활한 사용을 위한 훈련과정

• 정책, 주제 그리고 업무 등에 관한 학습 워크숍

- 상담 프로그램 
- 출장 결과 보고서

- 향후의 업무개선을 위하여 퇴직 예정자와 인터뷰 프로그램

- 데이터베이스

- CIDA 인터넷 사이트와 인트라넷

- 이메일

- 개발협력 전문가 커뮤니티(Community of Practice)와 실무그룹들이 사용할 수 있는 엑스트라넷

- 워크숍, 세미나, 오전회의 그리고 기타의 비공식적인 지식공유 활동들

\section{5) Practical Action(ITDG)}

'적정기술개발그룹(Practical Action)' 은 적정기술을 활용하여 개발도상국의 빈곤문제에 대 처하고자 하는 비정부기구이다. 여기서는 기술을 기반시설, 기계 그리고 장비와 같은 물리적인 것뿐만 아니라 관련된 지식과 이 모든 것들을 운용할 수 있는 능력까지 포함하는 것으로 정의하 고 있다. 이에 따라 'Practical Action' 에서는 지식공유를 조직의 사명(Mission)에 반영하고 있는데, 이것은 다음의 문장을 통하여 확인 할 수 있다.

Practical Action(ITDG)은 기술을 개발하고 사용하며, 결과를 중시하고 지식을 공유하며 다 름 사람들에게 혜택을 줌으로써 개발도상국의 빈곤을 퇴치하는 것을 목적으로 한다.

이와 관련하여 'knowledge, impact, Influence'라는 부제를 가진 Practical Action의' 2003 2007 전략보고서 '에서는 지식이 조직의 목적을 달성하기 위한 핵심적인 요소임을 분명 히 하고 있다.

영국의 본부와 세계 각국에 해외 사무소가 있는 구조로 인하여 'Practical Action' 은 이들 간의 지식공유가 매우 중요하다는 인식을 하고 있다. 이를 위하여 'Learning Before Learning During - Learning After' 라는 프레임워크가 제공되고 있으며, 이 프레임워크 안 에서 다양한 활동들이 진행되고 있다. 이러한 활동 중의 하나로는 사업의 기획과정에서 지식과 정보의 수집 및 조사에 초점을 맞춘' 6 단계 프로젝트 사이클(six-stage project cycle) ‘을 들 수 있다.

지식공유를 위한 조직의 구조와 관련해서는 범분야(Cross-cutting)에 걸친 차별화된 주제를 다루기 위한 목적으로 구성된 'New International Programme Teams' 는 조직의 지식창조 
와 지식공유를 위한 틀(Platform)을 제공하고 있다. 'International Programme Teams' 의 리더들은 1년에 한 번씩 핵심적인 주제에 관한 토론과 공유를 위하여 모임을 가진다. 이와 유사 하게 해외사무소의 책임자들로 구성된 ‘Group management team’ 은 1년에 두 번씩 전략적 리더십에 관한 토의를 위하여 모임을 가지고 있다.

'Practical Action' 은 다양한 비공식적인 지식공유 활동들을 전개하고 있다. 예를 들어 ‘story gathering team' 은 모든 직원들이 업무나 해외 출장 등을 마치고 나면 인터뷰를 통하 여 성과를 수집하고 이를 공유하고 있으며, 해외 사무소에서 관련된 주제들에 대한 내용을 공유 하기 위한 프리젠테이션을 수행하고 있다. 또한 토론과 세미나 등이 개최되고 있으며, 매주 이 메일 토론을 통하여 '최고관리자(Chief Executive Officer)' 와 의견을 나누기 위한 토론이 진 행된다.

한편 직원들의 지식공유에 대한 인식을 높이고 이를 업무에 적용하기 위하여 개개의 직원들에 게 지식공유를 위한 훈련과정이 제공되고 있으며, 지식공유를 직원의 핵심적인 역량으로 평가 하는 인사관리 체계가 적용되고 있다.

Practical Action에서 수행되고 있는 지식공유 활동의 예로는 다음과 같은 것들이 있다.

- 매트릭스 구조로 조직 재정비

- 교육용 $\mathrm{CD} \mathrm{ROM}$ 제공

- 지식공유에 기반을 한 프로젝트 사이클

- 성과관리 시스템

- 지식공유 활동에 대한 직원 포상

- 개발협력 전문가 커뮤니티(Communities of practice) 운영

- 업무 종료 및 출장 후의 인터뷰와 자료생성

- 핵심 사항들에 대한 주간 PPT 프리젠테이션 공유

- 최고관리자 $(\mathrm{CEO})$ 주관 하에 주제별, 분야별 이슈들에 대한 주간 토론

- 데이터베이스

- 웹사이트

- 인트라넷

- 사용자 간 정보통신 기술 호환성 강화 및 문서 공유

- 사용자 맞춤형의 프로젝트 트래킹 시스템 구축 


\section{6) 국제 농업연구 컨설팅 그룹(CGIAR)}

농업은 현재 전 지구적인 시장화, 새로운 정보통신 기술의 확산, 사회적, 경제적, 정치적 그리 고 환경적인 변화라는 도전에 직면해 있다. 농업을 둘러싼 이러한 도전에 대응하기 위하여 '국 제 농업연구 컨설팅 그룹(Consultative Group on International Agricultural Research, CGIAR)' 은 조직을 지식공유 친화적으로 만들기 위한 노력을 하고 있으며, ‘최고정보관리자 (Chief Information Officer)' 를 만들어 기관의 지식정보 전략을 담당하게 하고 있다.

CGIAR에서 지식공유를 활성화하기 위한 시도로는 'Organizational Change Program(OCP)', 'Institutional Learning and Change(ILAC) Initiative', 그리고 'Information \& Communication Technology- Knowledge Management(ICT-KM) program'을 들 수 있다.

우선 포드 재단(Ford Foundation)의 지원 하에 수행된 OCP는 지식공유를 위해서는 인간중 심적인(people-focused) 접근이 중요하다는 인식에 따라 개발협력 전문가 커뮤니티 (Community of Practice)에 대하여 지원을 하는 사업이다. OCP의 지원을 바탕으로 개발협력 전문가 커뮤니티는 농업 연구 및 개발과 관련된 다양한 주제들에 대한 토론을 활성화하고, 지식 공유를 포함한 창의적인 해결책들을 찾아내기 위한 노력을 진행하였다. 개발협력 전문가 커뮤 니티를 활용한 지식공유의 노력은 여러 낭비적인 요소들을 줄이고, 연구 사이클(Research Cycle)의 단계를 축소시켰으며, 외부 개발파트너들과의 관계를 강화하는 성과를 거두었다.

'ILAC Initiative' 는 CGIAR의 목적인 농업을 이용한 빈곤퇴치를 달성하고, 학습을 통하여 개인, 집단, 조직의 차원에서 성과를 향상시키기 위하여 연구를 더욱 효과적으로 수행하고자 하 는 시도이다. 이러한 시도는 실용성있는 연구와 혁신적인 업무개선을 통하여 지식공유에 대한 인식을 높이고, 역량을 강화시키는 성과를 거두어 왔다. 이것은 또한 기획과 평가(planning and evaluation) 담당자들에게 실질적인 도움이 되고 있다.

지금까지 CGIAR의 연구들은 전 세계에 걸쳐 있는 연구소들이 개별적으로 연구를 진행하는 경향에 따라 연구의 성과가 분절화되고 시너지 효과를 내기가 어렵다는 평가를 받아 왔다. 이를 개선하기 위하여 ICT-KM program은 팀 업무(teamwork)와 지식공유를 확대하고, 상호학습 의 문화를 정착시켜, 개별 연구소 차원의 연구들을 지식공유에 기반을 한 CGIAR 전체 시스템 차원의 연구로 전환하는 노력을 하였다. 
ICT-KM과 ILAC Initiative는 개별 연구자 및 사업에서부터 CGIAR 전체를 관장하는 정책 과 모든 운영에 걸친 다양한 차원에서 변화를 이끌어내고 있다. 이렇게 지식이 CGIAR 업무의 핵심적인 요소가 됨에 따라 지식공유는 CGIAR의 성공에 점점 더 중요해지고 있으며, 투자할 만한 가치가 있는 것으로 평가받고 있다.

\section{5. 결론}

우리는 지금까지 개발협력 분야의 지식공유와 관련된 역사적인 맥락, 개념 그리고 이와 관련 된 기관들의 활동과 동향들을 살펴보았다. 지식의 공유는 1990 년대 이후에 진행되어 온 새로운 개발방식에 대한 다양한 논의들 중의 하나이다.

이 시기에 국제사회는 유엔 중심의 개발원조로부터 벗어나 유럽연합, 국제무역기구, G8 등이 개발원조의 새로운 주체로써 등장하였으며, 개발원조는 빈곤과 보건 같은 분야 별 프로그램 중 심이 아닌 정책이 중심이 되는 방향으로 변화하였으며, 정책대화 등을 통하여 수원국의 주인의 식을 중요시하는 방향으로 전환되었다. 이러한 외적인 변화들은 필연적으로 개발협력 기관들이 기존에 수행해 오던 조직운영과 개발원조의 방식을 변화시켜야 한다는 요구에 직면하게 만들었 다.

이러한 변화에 대응하기 위하여 새로운 개발원조의 지식들이 필요하게 되었으며, 정보통신 기 술의 혁명은 개발원조를 담당하는 기관들이 새로운 변화에 대응하고 지식을 효과적인 개발원조 의 핵심적인 요소로 인식하게 만드는 중요한 역할을 하였다. 기관들은 내부적으로 지식관리(지 식공유)를 조직의 운영방식에 도입하여 개발원조의 효과성을 요구하는 비판에 대응하였으며, 외부적으로 기관 간, 공여기관과 수원국 사이의 지식공유를 통하여 선진국의 일반적인 지식과 경험이 아닌 수원국의 환경에 적절한 개발원조를 수행하고자 한다.

지금까지 수행되어 온 국제사회의 지식공유 노력들을 평가해 보자면, 내부적 지식공유가 조직 의 효과적인 운영에 얼마나 영향을 주었는지에 대해서는 논란들이 있지만, 이의 시행을 통하여 많은 긍정적인 변화들이 나타난 것은 분명하다. 과거에 비하여 조직 내의 담당자들은 다양한 협 업을 통하여 더 효과적으로 업무를 수행하고 있으며, 인트라넷 같은 기반시설들은 발전하였으 며, 본부와 현지사무소 간의 연결성은 더 증대되었다. 
그러나 아직 많은 기관들은 내부적 지식공유를 지나치게 인트라넷의 설치나 정보통신 기술의 이용 등 기반시설의 구축이라는 관리적이고 기술적인 측면에 치중하고 있다. 또한 지식공유에 활용되는 지식도 지식공유에 중요한 암묵적인 지식보다는 명시적인 지식이나 데이터 자체가 더 선호되고 있다. 내부적 지식공유의 성공여부는 조직 내 직원들 간의 상호작용이 얼마나 질적으 로 잘 연결되어 있는지와 유용한 암묵적 지식을 얼마나 잘 활용하는지에 좌우된다.

그리고 가장 중요한 것은 조직 내의 문화가 지식을 활용하고 공유하는 것에 더 많은 가치를 두도록 변화하는 것이다. 이를 위해서는 지식공유의 활성화를 조직의 핵심적인 가치로 설정하 는 리더십이 중요하며, 직원들에게 지식의 공유는 새로운 업무를 부과하는 것이 아니라 업무를 더 효과적으로 수행할 수 있게 하는 것이라는 인식을 확산시키는 것이 필요하다.

한편 컨퍼런스 개최, 수원국과의 공동연구, 인터넷을 통하여 지식공유의 장을 제공하는 등의 수단을 통한 성공적인 외부적 지식공유의 사례는 다양하게 존재하고 있다. 그러나 많은 경우에 이러한 성공들은 외부적 지식공유를 명시적으로 천명하는 개발협력 기관들의 정책이나 전략 없 이 수행되어 왔으며, 기관의 정책이나 전략 부재가 외부적 지식공유를 방해하는 요소로 작용한 것도 아니다.

사실 외부적 지식공유를 위한 수단들은 국제사회에서 지식의 공유가 개발의 중요한 요소로 각 광받기 이전부터 존재해 온 것들이다. 따라서 이상적으로는 이러한 외부적 지식공유가 수원국 의 역량개발과 효과적인 개발에 필수적인 것이라 하더라도, 이의 긍정적인 영향력을 독립적으 로 판단하는 것은 쉬운 일이 아니다. 다만 성공적인 개발지식과 경험을 보유하고 있는 한국의 입장에 비추어 본다면, 이를 수원국들과 나누기 위한 일환으로써 외부적 지식공유를 활성화시 키는 것은 한국과 $\mathrm{KOICA}$ 의 개발협력 사업이 발전할 수 있는 중요한 수단의 하나임은 분명할 것이다.

지식의 공유를 통한 개발협력은 국제사회에서 계속 발전해 나가고 있는 새로운 개념이다. 따 라서 다른 공여기관들과 마찬가지로, 한국의 개발협력 사업 중에서 무상원조를 전담하고 있는 $\mathrm{KOICA}$ 에도 효과적인 개발협력 사업을 위한 내외부적인 지식공유는 하나의 새로운 도전이자 도약을 위한 발판이라 할 수 있다. 


\section{참고문헌}

\section{1. 국내문헌}

이현주. 2009. "KOICA 사업의 삼각협력 추진방안." 한국국제협력단.

한국국제협력단. 2007. “국제협력단 정보화전략계획 수립 최종보고회 발표자료."

한국국제협력단. 2010. "KOICA 선진화 계획: 2010-2015."

한국국제협력단. 2012. "정보화부문 선진화를 위한 정보화전략계획 수립(ISP) 착수 보고회."

\section{2. 국외문헌}

ADB. 2004. "Knowledge Management In ADB.” Asian Development Bank.

ADB. 2007. "Knowledge-Sharing Program Using good Asian Proactives in Innovation and Development." Asian Development Bank.

ADB. 2009. "Learning for Change in ADB." Asian Development Bank.

ADB. 2009. "Enhancing knowledge Management under Strategy 2020." Asian Development Bank.

ADB. 2010. “Annual Report 2010: Volume 1.” Asian Development Bank.

ADB. 2011. "Assessment of ADB's Knowledge Management Implementation Framework." Asian Development Bank.

ADB. 2011. "Guidelines for Knowledge Partnerships." Asian Development Bank.

Aubert, Jean-Eric. 2005. "Promoting Innovation in Developing Countries: A Conceptual Framework." World Bank.

Ballantyne, Peter. 2002. "Collecting and Propagating Local Development Content: The Case Stories." DFID.

Barnard, Geoff. 2003. "Knowledge Sharing in Development Agencies : Knowledge fortress of Knowledge pool?" Information Development 19:280.

Boom, Daan. 2005. "The Asian Development Bank's knowledge management framework." Asian Development Bank. 
Britton, Bruce. 2005. "Organizational learning in NGOs: creating the motive, the means and opportunity." Praxis paper, Oxford.

Browne, Stephen. 2002. "Developing Capacity Through Technical Cooperation: Country Experiences." UNDP, London.

Chen, Derek H.C. and Carl J. Dahlman. 2005. "The Knowledge Economy, the KAM Methodology and World Bank Operations." World Bank, Washington D.C.

CIDA. 2003. "Knowledge Sharing: methods, Meetings and Tools." Canadian International Development Agency.

CIDA. 2007. "CIDA's Strategy on Knowledge for Development Through Information and Communication Technologies." Canadian International Development Agency.

Cummings, Jeffrey. 2003. "Knowledge Sharing: A Review of the Literature." World Bank, Washington D.C.

Darrow, K. and Saxenian, M. 1990, Appropriate Technology Source Book. Westview Press.

Development GATEWAY. 2010. "Innovation for a New Decade: Annual Report 2010." Development Gateway.

DFID. 2005. “Knowledge Sharing Strategy DFID.” DFID, London.

ECOSOC. 2008. "Background Study for the Development Cooperation Forum: Trends in South-South and triangular development cooperation."

Felder-Gray, Denise. 2001. "Making Waves: Stories of Participatory Communication for Social Change."

Ferguson, Julie E. and Sarah Cummings. 2007. "Knowledge management in practice: the case of international development." Alex Koohang(Ed). Knowledge management. The Informing Science Press. Santa Rosa, California.

G-20 Development Working Group. 2011. "Scaling Up Knowledge Sharing for development: A Working Paper for the G20 Development Working Group, Pillar 9.”

Henderson, Kim. 2005. "The Knowledge sharing approach of the United Nations Development Programme." KM4D.

Hendricks, Paul. 1999. "Why Share Knowledge? The Influence of ICT on the Motivation for Knowledge Sharing." Knowledge and Process Management.

High Level Event on South-South Cooperation and Capacity Development. 2010. "Bogota Statement: Towards Effective and Inclusive Development Partnerships." 
Hovland, Ingie. 2003. "Communication of Research for Poverty Reduction: A Literature Review." ODI, London.

Hovland, Ingie. 2003. "Knowledge Management and Organizational Learning: An International Development Perspective." ODI, London.

IKMemergent. 2009. "Knowledge for development in Africa: Challenges and opportunities." IKMemeggent

JICA. 2005. "Thematic Guidelines on South-South Cooperation." Japan International Cooperation Agency, Tokyo.

JICA. 2010. “Annual Report 2010.” Japan International Cooperation Agency, Tokyo.

Juma, Calestous and Lee Yee-Cheong. 2005. "Innovation: applying knowledge in development." EARTHSCAN, London.

King, Kenneth and Simon McGrath. 2004. Knowledge for Development?: Comparing British, Japanese, Swedish and World Bank aid. HSRC Press. Cape Town. South Africa.

King, Kenneth and Simon, McGrath. 2003. "Knowledge Sharing in Development Agencies: Lessons from Four Cases." World Bank, Washington D.C.

King, Kenneth. 2000. “Towards Knowledge-based Aid: A new way of working or a new North-south divide?" CICE Hiroshima University.

King, Kenneth. 2004. "Development Knowledge and the Global Policy Agenda. Whose Knowledge? Whose Policy?." UNRISD, Geneva.

Kingo Mchombu, Julie E. Ferguson and Sarah Cummings. 2008. "Meta-review and scoping study of the management of knowledge for development." IKMemergent, Netherlands.

Knowledge Strategy Group. 2010. “Transforming the Bank’s Knowledge Agenda: A Framework for Action." Knowledge Strategy Group.

Krobwinkel-Karlsson, Anna. 2007. "Knowledge and Learning in Aid Organizations: A literature review with suggestions for further studies." SADEV, Swedish.

Kuznetsov, Yevgeny and Carl. J. Dahlman. 2008. "Mexico's transition to a knowledge-Based Economy: Challenges and Opportunities." World Bank, Washington, D.C.

Lamoureux, Lucie. 2006. "Developing Capacity for the use of knowledge sharing approaches and techniques." KM4D.

Laporte, Bruno. 2004. "The Knowledge Bank in Action." World Bank, Washington, D.C.

OECD. 2006. "The Challenge of Capacity Development: Working Towards Good Practice." OECD, Paris. 
OED. 2003. "Sharing Knowledge: Innovations and Remaining Challenges." World Bank, Washington, D.C.

OED. 2003. "Sharing Knowledge to Achieve development Goals." World Bank, Washington, D.C.

Pasteur, Katherine. 2004. "Learning for development: A literature review." IDS, Brighton.

Perkin, Emily and Julius, court. 2005. "Networks and Policy Processes in International Development: a literature review." ODI, London.

Powell, Mike. 2006. "Which knowledge? Whose reality? An overview of knowledge in the development sector". Development in Practice. 16(6): 518-532.

Quaggiotto, Giulio. 2005. "Elective affinities? Reflections on the enduring appeal of knowledge management for the development sector". Knowledge Management for Development Journal. 1(3): 41-45.

Ramalingam, Ben. 2006. "Tools for Knowledge and Learning: A guide for Development and Humanitarian Organizations." ODI, London.

Scarf, Charlotte and Kelly, Hutchinson. 2003. "Knowledge networks for development: A participatory design approach.” ICCK, Alexandria.

Serrat, Olivier. 2010. “Crafting a Knowledge Management Results Framework.” ADB.

Serrat, Olivier. 2010. "Knowledge Solutions: Tools, Methods, and Approaches to Drive Development Forward and Enhance Its Effects." ADB.

Serrat, Olivier. 2010. "Learning in Development.” ADB.

Stone, Diane. 2005. "The Knowledge Bank and the Global Development Network." University of Warwick.

Suh, Joonghae and Derek H.C. Chen. 2007. "Korea as a Knowledge Economy: Evolutionary Process and Lessons Learned." KDI and World Bank, Washington, D.C.

Talayhan, Surmaya and David J. Grimshaw and Lucky Lowe. 2005. "Reaching the last mile: Knowledge Sharing for development."

Talisayon, Serafin D. 2009. "Monitoring and Evaluation in Knowledge Management for Development." IKMemerqent, Netherlands.

TT-SSC. 2010. "Analytical work of the TT-SSC: Informing policy for th HLF Busan and beyond." TT-SSC.

TT-SSC. 2010. "Boosting South-South Cooperation in the Context of Aid Effectiveness." TT-SSC. 
UNDP. 2006. "Sharing Innovative Experiences.: Examples of knowledge sharing for Local Development in the South." NY. USA. UNDP.

UNDP. 2008. "Sharing Innovative Experience: Examples of Community-based Approaches to Recovery from Natural Disasters - Post-tsunami Experiences." UNDP.

UNDP. 2008. "Sharing Innovative Experience: Examples of Successful Publicprivate Partnerships." UNDP.

UNDP. 2008. "Sharing Innovative Experience: Successful Social Protection Floor Experiences." UNDP.

UNDP. 2009. “Capacity Development: A UNDP PRIMER.” UNDP.

UNDP. 2009. "Enhancing South-South and Triangular Cooperation: study of the current Situation and Existing Good Practices in Policy, Institutions, and Operation of South-South and Triangular Cooperation." UNDP, New York.

Unwin, Tim. 2007. "No end of Poverty". Journal of Development Studies. 43(5): 929-953.

WBI. 2010. "Capacity Development and Results Framework." World Bank, Washington, D.C.

WBI. 2007. "Building Knowledge Economics: Advanced Strategies for Development." World Bank, Washington, D.C.

World Bank. 1998. "Knowledge for Development: World Development Report." World Bank, Washington, D.C.

World Bank. 2010. "Development Outreach: Putting Knowledge to Work for Development." World Bank, Washington, D.C.

World Bank. 2011. "The State of World Bank Knowledge Services: Knowledge for Development." World Bank, Washington, D.C.

World Bank. 2011. "Using Knowledge Exchange for Capacity Development : What Works in Global Practice?." KDI and World Bank, Washington, D.C.

World Bank. 2012. "The art of knowledge exchange: A results-focused planning guide for development practitioners." World Bank, Washington, D.C. 